\title{
New deeply coloured 18-K gold materials built by nanotechnologies
}

\author{
Anne Serin - Mathieu Bourlion - Frédéric Diologent • \\ René Ziegenhagen • Vincent Germain
}

Published online: 12 December 2014

(C) The Author(s) 2014. This article is published with open access at SpringerLink.com

\begin{abstract}
A new way to elaborate coloured carat gold materials has been developed. Instead of using traditional metallurgy route, we built a new 18-K bulk material using nanostructured gold particles. The resulting colour is the consequence of a well-known property of gold nanoparticles: the surface plasmon resonance effect. Depending on the chemical environment around the nanoparticles, their shape and size, it is possible to tune the colour of gold. Thanks to this property, it is possible to obtain a large panel of colours not achievable via conventional alloying route. Here, we focus on one hybrid nanostructured material: $\mathrm{Au}-\mathrm{SiO}_{2}$. The development of a new synthesis route enables us to obtain nanostructured micrometric powders that can then be pressed to obtain a bulk material. The resulting nanocomposites are characterized by means of energy-dispersive X-ray spectroscopy (EDX), fire assay, TEM and spectrophotocolorimetry. All these characterizations have shown that our composites exhibit a gold content superior to $75 \%$ by weight and have a much more vivid colour than classical coloured gold. The new composites are therefore deeply coloured $18-\mathrm{K}$ materials.
\end{abstract}

Keywords Coloured gold · 18-Kgold · Gold nanocomposite · Gold nanoparticles $\cdot$ Surface plasmon resonance

\section{Introduction}

Since the earliest time, due to humanity's attractiveness for gold, this noble metal had received a lot of attentions in

A. Serin $\cdot$ M. Bourlion $\cdot$ V. Germain $(\bowtie)$

NEOLLIA SAS, 8 rue de l'Ecole Normale, 34296 Montpellier CEDEX, France

e-mail: germain@neollia.com

F. Diologent $\cdot$ R. Ziegenhagen

CARTIER, 35-37 rue Boissy d'Anglas, 75008 Paris, France particular from alchemists and metallurgists. Alchemists were looking for potable gold [1] and transmutation [2-4]; metallurgists were looking into new kind of gold alloy. One of the most important phase diagrams is the well-known Au-Ag-Cu ternary system [5]. This metallurgical system consists in an eutectic system $(\mathrm{Ag}-\mathrm{Cu})$ and two binary complete solid solutions ( $\mathrm{Au}-\mathrm{Ag}$ and $\mathrm{Au}-\mathrm{Cu}$ ). Thus, at any temperature, as long as the metal is solid, the ternary system displays either a single-phase ternary solid solution or a biphasic region [6] (Au-Cu diagram displays organized phases as shown in [6]). The yellow, red and green colours achievable with this system are obtained by varying the ratio of $\mathrm{Au}, \mathrm{Ag}$ or $\mathrm{Cu}$, as shown on the gold triangle (Fig. 1) [7, 8]. More colour variations can be obtained by the addition of nickel $(\mathrm{Ni})$, zinc $(\mathrm{Zn})$, palladium $(\mathrm{Pd})$, cadmium $(\mathrm{Cd})$ or manganese (Mn). However the incorporation of nickel, cadmium and manganese is not desirable. Nickel and manganese are allergens; cadmium oxide $(\mathrm{CdO})$ is very toxic and irritant to the respiratory system, causes damages to the kidney and is carcinogen [9]. Thus, if the alloy has to be at least $12 \mathrm{~K}$, the attainable colour range is restricted.

The colour of typical metals is described as such: high luminance, very desaturated and dominant wavelengths are of a very limited range. A colour can be reproduced by mixing white light with spectrally pure light. Different proportions give a range of saturation, from white $(0 \%$ of the spectrally pure light) to the spectrally pure shade (100\% spectrally pure light) which is the most intense colour available of that hue. Saturation refers to the position on the scale. The dominant wavelength describes the hue. Luminance is a technical term which correlates well with brightness [6].

It is possible to obtain gold with higher levels of saturation with intermetallic compounds [9-12]. The most famous one is the purple gold, which is formed of $79 \mathrm{wt} . \% \mathrm{Au}$ and $21 \mathrm{wt} . \%$ $\mathrm{Al}$ : $\mathrm{AuAl}_{2}$ [13]. The gold content being above 75 wt.\%, it is considered as an 18-K alloy. Blue gold can be obtained with the following two intermetallic compounds: $\mathrm{AuGa}_{2}$ and 


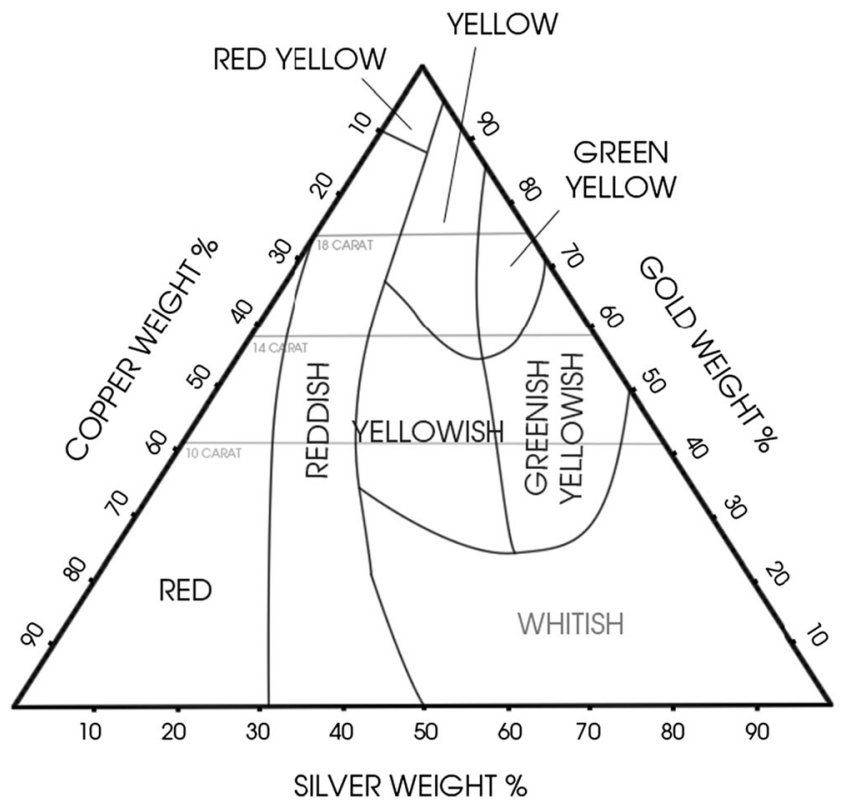

Fig. 1 The gold triangle. Relationship between composition and colour in the $\mathrm{Au}-\mathrm{Ag}-\mathrm{Cu}$ ternary alloy system showing the limited range of colour achievable via classical alloying

$\mathrm{AuIn}_{2}$. None of them can be considered as $18-\mathrm{K}$ gold alloys since their gold content is respectively 58.5 and $46 \mathrm{wt} . \%$. In any case, those alloys are very difficult to work with in traditional jewellery or watchmaking techniques since they are very brittle. As a consequence, they are often faceted and used as gemstones or inlays. Table 1 summarizes the different coloured gold obtained by alloys and/or intermetallic compounds.

A third method to obtain coloured gold alloys is through the surface oxide layers $[9,10]$. After a heat treatment in air, some atoms of the alloyed metals can move to the surface and form oxides. This can lead to deep colours such as blues, browns, blacks and greens. Elements used in the alloys can be one of the following: cobalt $(\mathrm{Co})$, nickel $(\mathrm{Ni})$, iron $(\mathrm{Fe})$, ruthenium $(\mathrm{Ru})$, chromium $(\mathrm{Cr})$ and so on. However, the oxide layers formed with this technique are usually very thin, leaving the pieces vulnerable to surface damage such as scratches or pitting. To our knowledge, those were the only ways to get coloured precious gold pieces with metallurgical methods.

Using the nanotechnology approach, a completely new range of deeply coloured gold can be obtained. In the past, large pieces of materials coloured by gold nanoparticles have been realized; one can cite the famous Lycurgus Cup (400 AD) [14-16] or the stained glass of the Cathédrale Notre Dame de Paris [17-19] (France). These pieces were realized by master glassmakers using gold salts. The colouration of the glass comes from the in situ reduction of these salts, leading to nanoparticles. However, the glassmakers did not know that they were using nanoparticles to colour their makings. It is

Table 1 Composition and colour of traditional gold alloys obtained through standard metallurgical methods

\begin{tabular}{|c|c|c|c|c|c|c|c|c|}
\hline \multirow[t]{2}{*}{ Name of the alloy } & \multicolumn{2}{|l|}{$\mathrm{Au}$} & \multicolumn{6}{|c|}{ Alloyed Elements } \\
\hline & $\%$ weight & Caratage & Nature & $\%$ weight & Nature & $\%$ weight & Nature & $\%$ weight \\
\hline $0 \mathrm{~N}$ & 58.50 & 12 & Ag & $30-34$ & $\mathrm{Cu}$ & $7.50-11.50$ & & \\
\hline $1 \mathrm{~N}$ & 58.50 & 12 & Ag & $24-26.50$ & $\mathrm{Cu}$ & $15-17.50$ & & \\
\hline $2 \mathrm{~N}$ & 75 & 12 & Ag & $15-16$ & $\mathrm{Cu}$ & $9-10$ & & \\
\hline $3 \mathrm{~N}$ & 75 & 18 & Ag & $12-13$ & $\mathrm{Cu}$ & $12-13$ & & \\
\hline $4 \mathrm{~N}$ & 75 & 18 & Ag & $8.50-9.50$ & $\mathbf{C u}$ & $15.50-16.50$ & & \\
\hline $5 \mathrm{~N}$ & 75 & 18 & Ag & $4.50-5.50$ & $\mathrm{Cu}$ & $19.50-20.50$ & & \\
\hline $6 \mathrm{~N}$ & 75 & 18 & $\mathrm{Cu}$ & 25 & & & & \\
\hline Yellow gold & 80 & 19.20 & Ag & 10 & $\mathrm{Cu}$ & 10 & & \\
\hline Green gold & 80 & 19.20 & Ag & 20 & & & & \\
\hline Red gold & 80 & 19.20 & $\mathrm{Cu}$ & 20 & & & & \\
\hline White gold & 80 & 19.20 & $\mathrm{Cu}$ & 10 & $\mathbf{N i}$ & 5 & $\mathbf{Z n}$ & 5 \\
\hline Red gold & 91.6 & 22 & $\mathrm{Cu}$ & 8.4 & & & & \\
\hline Yellow gold & 91.6 & 22 & Ag & 5.5 & $\mathrm{Cu}$ & 2.9 & & \\
\hline Grey gold & 75 & 18 & Ag & 15 & $\mathrm{Cu}$ & 10 & & \\
\hline Red gold & 75 & 18 & Ag & 10 & $\mathbf{C u}$ & 15 & & \\
\hline Green gold & 75 & 18 & Ag & 25 & & & & \\
\hline Purple gold $\left(\mathrm{AuAl}_{2}\right)$ & 79 & $>18$ & Al & 21 & & & & \\
\hline \multirow[t]{2}{*}{ Blue gold } & 46.00 & $<12$ & In & 54 & & & & \\
\hline & 58.50 & $<18$ & Ga & 41.50 & & & & \\
\hline \multirow[t]{2}{*}{ White gold (rhodiumized) } & 75 & 18 & Pd & 15 & Ag & 10 & & \\
\hline & 75 & 18 & Pd & 25 & & & & \\
\hline
\end{tabular}


only a few hundred years later, thanks to new analysis methods, that it has been discovered that the gold nanoparticles were giving the colour to the glass. The aforementioned pieces of fine art cannot however be qualified as precious from a jewellery point of view as they contain a low amount of gold.

The special colouration of these pieces is obtained through the surface plasmon resonance (SPR) effect. When metal nanoparticles are submitted to an electromagnetic field, they polarize. This leads to the collective oscillation of electrons at the surface of the nanoparticles. A specific frequency of the electromagnetic field is absorbed by the plasmon oscillations: this frequency is named the surface plasmon resonance. Thus, macroscopically, nanoparticles present an opposite colour to the absorbed frequency. The SPR depends on several parameters, such as the nature of the metal, the shape $[19,20]$ and the polarizability $[21,22]$ of the particle, its surface as well as its environment [20, 23, 24].

The surface plasmon resonance of gold nanoparticles has been extensively studied in the last few decades. Turkevich has presented a robust method to synthesize gold nanospheres [25], the resulting solution usually presents a single SPR around 520-530 nm. Since then, numerous methods based on Turkevich's one have been developed [26-29]. They mostly provide well-defined spherical gold nanoparticles. However, spheres are not the only shape that can be synthesized. Depending on the experimental conditions, cubes [30], decahedrons [30], octahedrons and rods [20,31,32] can also be obtained. Each shape and size [20] synthesized presents specific absorption spectra. Thus, depending on all these parameters, colours like blue, purple, pink, red or even green are obtainable [33].

This specific colour property has given rise to the use of gold nanoparticle as a pigment for various applications from the coloration of wool [34] to the coloration of paint [35].

Several attempts of using gold nanoparticles in the jewellery industry have been done. One can cite the use of gold nanoparticles as a pigment for ceramics with a content up to $5 \%$ in mass [36]. However, with this attempt, they were not able to produce a material containing $75 \%$ in mass of gold.

In this paper, we report a new method to obtain deeply coloured gold powders thanks to the SPR effect of gold nanoparticles. The innovation here is that we work with silica-coated gold nanoparticles instead of classic bulk gold alloyed with different elements. Indeed, the addition of a dielectric shell (silica) around the gold nanoparticles modifies the SPR effect, allowing us to obtain different colours. The gold content can be fine-tuned from 50 to $90 \mathrm{wt} \% \%$ by controlling the thickness of the dielectric shell. The approach developed here is a two-step method: the gold nanoparticles are first produced and then coated. After precipitation, the particles are filtered, dried, annealed and then can be pressed into pellets so as to obtain a bulk material.

\section{Experimental section}

\section{Characterization material}

The annealed powders are characterized using a Philips CM20, $200 \mathrm{kV}$ equipped with a $\mathrm{LaB}_{6}$ filament transmission electron microscope. The powder is directly put on the TEM grid without the use of a solvent.

The obtained pellets are imaged using a JEOL JCM-6000 equipped with energy-dispersive X-ray spectrometry (EDX) operating at $15 \mathrm{kV}$; the EDX analysis is performed on the same apparatus.

The colour determination was carried out on a spectrophotocolorimeter, Konica Minolta CR-5, D65 light source, $10^{\circ}$ observation. The spectral curve is obtained on a Konica Minolta CM-5 spectrophotocolorimeter, D65 light source, $10^{\circ}$ observation, specular included.

Fire assay test was carried out by Bureau Central du Contrôle des Métaux Précieux of Switzerland (Berne, Switzerland).

\section{Chemicals}

The ultrapure water comes from a MQ-8 apparatus and has a resistivity of $18.2 \mathrm{M} \Omega \mathrm{cm}^{-1}$ (ultrapure water), Merck Millipore. Hydrogen tetrachloroaurate (III) $\left(\mathrm{HAuCl}_{4} \cdot 3 \mathrm{H}_{2} \mathrm{O}\right.$, $99.99 \%$ ) is purchased from Sigma Aldrich. Tetraorthosilicate (TEOS), $N, N$-dimethylformamide (ReagentPlus, $\geq 99 \%$ ) and tri-sodium citrate (ACSreagent, $\geq 99 \%$ ) were purchased from Sigma Aldrich. Isopropyl alcohol is obtained from Carlo Erba. Ammonium hydroxide solution $\left(28 \% \mathrm{NH}_{3}\right)$ is purchased from Alfa Aesar. All the reagents are used as received, without any further purification.

\section{Au stock solution}

A stock solution of $250 \mathrm{~g}$. $\mathrm{L}^{-1}$ gold (III) chloride hydrate is made with ultrapure water.

\section{Synthesis of nanoparticles}

The synthesis A1 is a two-step process derived from the Turkevich's method [25-27]: the nanoparticles are synthesized before they are coated with silica. It is performed in a $60 \mathrm{~L}$ glass line reactor. The reactor is filled with $16.3 \mathrm{~L}$ of ultrapure water and $11.78 \mathrm{~mL}$ of the gold stock solution. The solution is thoroughly mixed and heated to the reflux point, around $130{ }^{\circ} \mathrm{C}$. Then, $0.686 \mathrm{~L}$ of a $2 \%$ tri-sodium citrate solution is added. The solution discolours and quickly turns red. The heating is maintained for a short period of time and then the solution is let to cool down. On cooling, $32.5 \mathrm{~L}$ of isopropyl alcohol is added to the reactor and then $13 \mathrm{~mL}$ of TEOS is added followed by $0.3 \mathrm{~L}$ of ammonium hydroxide solution. The solution quickly turns dark 
blue. After a certain time of mixing, small dark-coloured flakes are forming in the solution. The reaction is then stopped and the solution is filtered. The precipitate is washed with ultrapure water. The dark-coloured cake is removed from the apparatus and put in a drying oven.

The entire powder obtained is then annealed under air in a muffle furnace $\left(800^{\circ} \mathrm{C}\right.$ for $\left.2 \mathrm{~h}\right)$. A coloured powder is obtained. Using the above synthesis and post thermal treatment, $1.6 \mathrm{~g}$ of coloured material is obtained.
Fabrication of pellets and sintering

To obtain a pellet, two batches of synthesis are mixed since about $3 \mathrm{~g}$ of material are sintered. The coloured powder is inserted in a 10-mm metallic die. The die is then placed under a uniaxial force of $60 \mathrm{MPa}$ for $10 \mathrm{~min}$. The obtained pellet is removed from the die and pre-sintered for $5 \mathrm{~min}$ in a muffle furnace previously set at $850^{\circ} \mathrm{C}$. A compact piece of material is obtained.
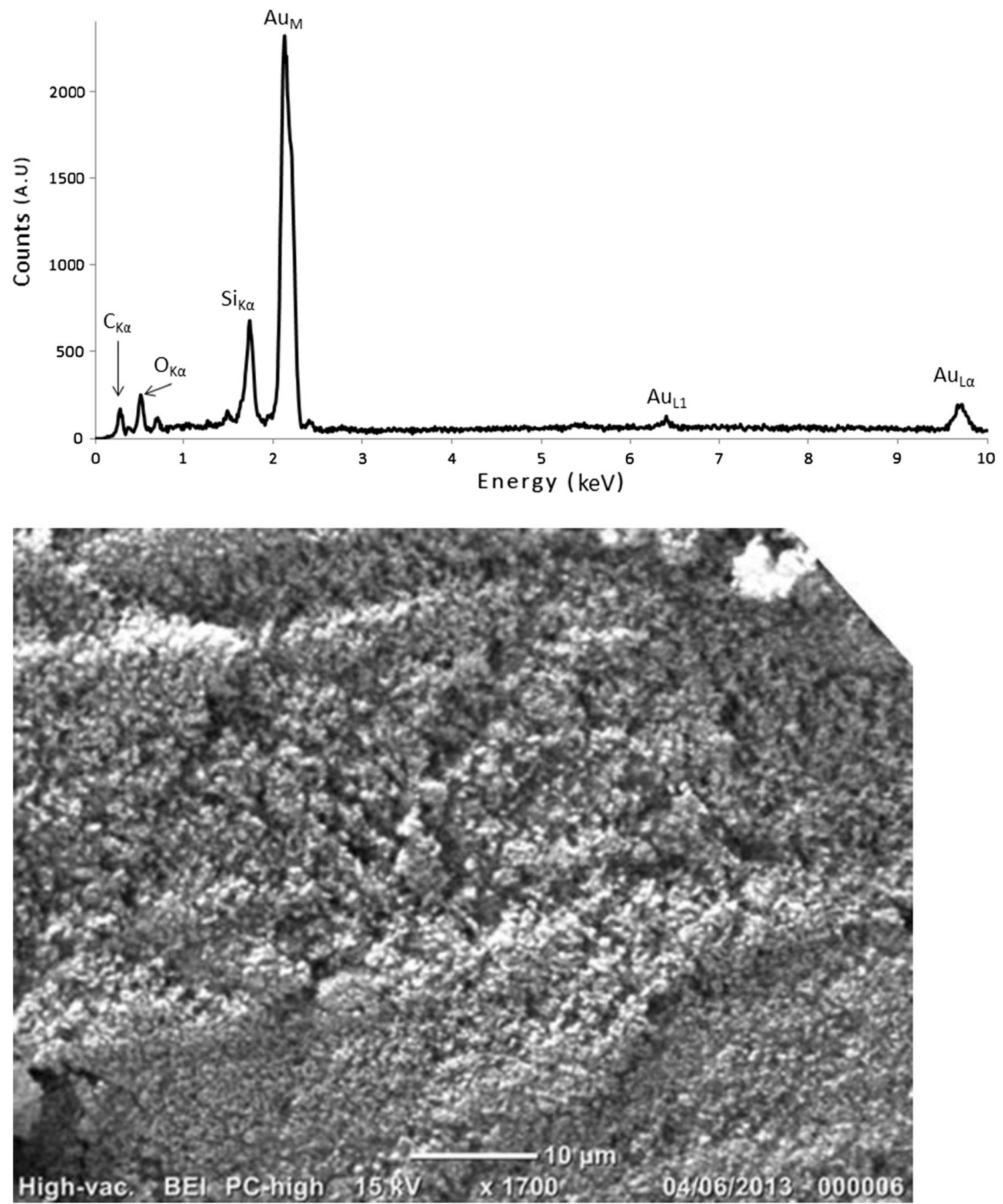

Fig. 2 EDX analysis coupled with a MEB observation of the synthesized powder 


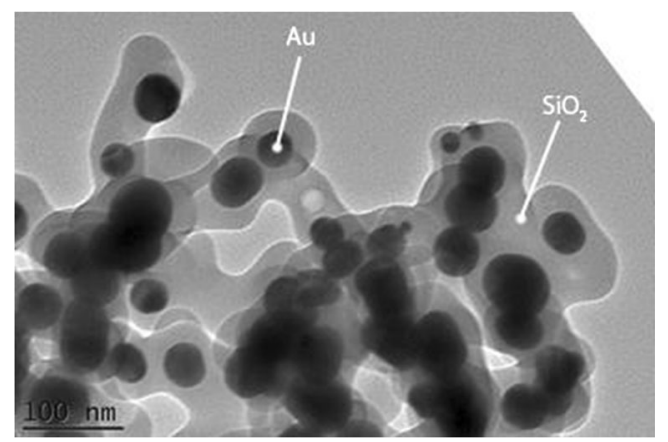

Fig. 3 Transmission electron micrograph of gold nanoparticles in a silica matrix

\section{Results and discussion}

Powder

To determine the composition of the synthesized powder, the samples are analysed by means of energy-dispersive X-ray spectrometry. The EDX analysis is presented in Fig. 2 as well as the SEM image of the acquired area. By tailoring the amount of silica precursor at a constant gold amount, it is possible to adjust the composition of the powder. Indeed, the less silica precursor (TEOS) is added, the higher the gold content will be, and reciprocally. Nevertheless, there is a minimum amount of ceramic precursor to add to the reaction as its role is to prevent the agglomeration of gold by coalescence or/and Ostwald ripening mechanisms. All the analysis results are gathered in Table 1.

Figure 3 shows typical images of the gold nanoparticles with their shell. They have been taken on the edge of the aggregate so that the electron beam could go through all the materials. The gold nanoparticles have a mean size of $50 \mathrm{~nm}$ and are surrounded by silica. This synthesis is a variation of the Turkevich method [25-27], one of the most studied and used method to produce gold nanoparticles. It means that the control of the nanoparticles size has been studied for a long time and therefore is easy to reach. It is worth noting that the gold nanoparticles are not individually coated with silica as expected for a regular core shell structure. This is a key advantage for us as the agglomerate microparticles can be easily filtered in our system. If the gold particles were individually coated, we would have to use centrifugation to collect them, which is much slower and not financially viable for industrial applications. It can also be noticed that in a ceramic flake, each gold nanoparticle is separated from another.

Using the same synthesis method but varying the amount of silica precursors and gold salt, different coloured gold powders were obtained (syntheses A2, A3 and A4 (Tables 1 and 2)). The colour of the powders is then measured with a spectrophotocolorimeter; this data is gathered in Table 1. This table shows three variations of the synthesis in which the silica precursor ratio has been tuned. This results in otherwise-coloured gold powders with a gold content varying between 12 and $18 \mathrm{~K}$. The comparison between these values and the ones presented in Fig. 4 shows a clear difference in terms of colour.

The annealing induces the densification of the ceramic surrounding the gold nanoparticles; this prevents the agglomeration by coalescence and/or Ostwald ripening mechanisms. Unless the ceramic coating is altered, there is no reason that this powder should evolve towards the formation of metallic gold chunks. Nevertheless, the heating temperature should not be excessive for a long period of time. The powder annealed at $1200^{\circ} \mathrm{C}$ for $2 \mathrm{~h}$ totally decolours due to the agglomeration of gold nanoparticles. Indeed, the gold and the silica present in the powder have completely demixed which results in gold pearls with silica particles.

\section{Pellet}

The silica-coated gold is then compacted and sintered. This is a key stage in our process. If the powder is pressed with a too important force, the silica flake can be damaged: the colour can be impaired and it can lead to the formation of classic yellow gold. Concerning the sintering, the conditions have to be optimized; this will be the subject of a further study.

The resulting pellet is then characterized in terms of gold content and colour. The gold composition is measured with two different methods. The first one uses a SEM equipped with EDX. This analysis is performed on a small chunk of the pellet. The measured gold content is $80.1 \mathrm{wt} . \%$. The obtained image and spectrum are compiled in Fig. 2. The second method used is the fire assay technique. Using this technique, a gold content above $87.8 \%$ was determined. A difference of gold rate can be noticed between the two method used. The
Table 2 Composition and colour of gold-based nanocomposite obtained via the new nanotechnology methods

\begin{tabular}{|c|c|c|c|c|c|c|}
\hline \multirow[t]{2}{*}{ Name of the alloy } & \multicolumn{2}{|l|}{$\mathrm{Au}$} & \multicolumn{2}{|c|}{ Nanocomposite composition } & \multicolumn{2}{|c|}{ Colour coordinates } \\
\hline & $\%$ weight & Caratage & Nature & $\%$ weight & $a^{*}$ & $b^{*}$ \\
\hline Synthesis A1 & 80.10 & 19.2 & $\mathrm{SiO}_{2}$ & 19.90 & 18.31 & 21.82 \\
\hline Synthesis A2 & 52.00 & $\sim 12$ & $\mathrm{SiO}_{2}$ & 48.00 & 22.05 & 30.20 \\
\hline Synthesis A3 & 85.00 & 20.4 & $\mathrm{SiO}_{2}$ & 15.00 & 16.77 & 30.20 \\
\hline Synthesis A4 & 70.00 & 16.8 & $\mathrm{SiO}_{2}$ & 30.00 & 20.24 & 17.76 \\
\hline
\end{tabular}




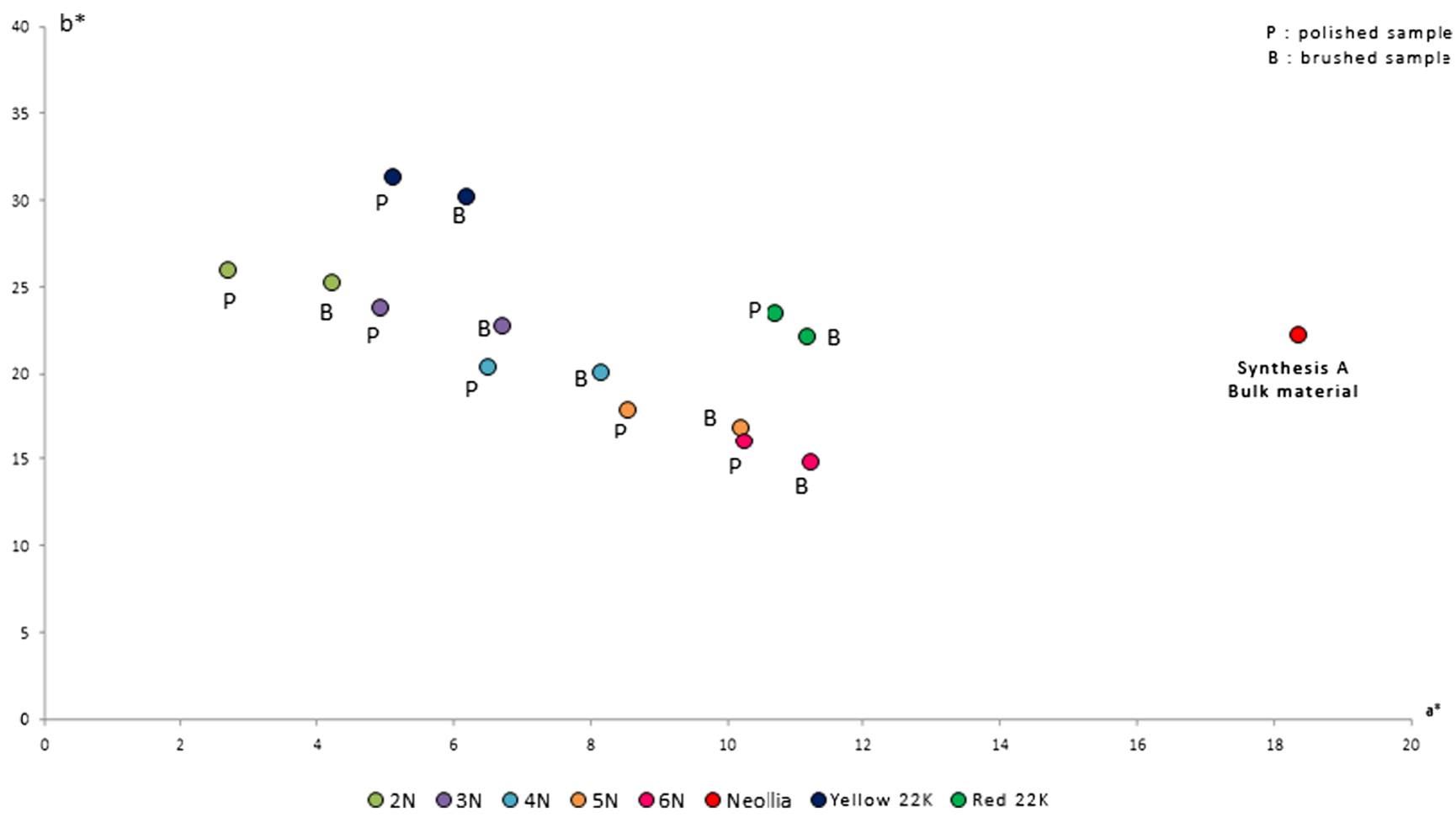

Fig. 4 Colour coordinates of Varinor standard gold alloys and of the presented material in the a*b* space (2N, 3N, 4N, 5N, 6N, 22-K yellow gold, 22-K red gold and A1-derived material)

EDX provides a lower gold content, which can be explained by the surface state of the analysed piece. Nevertheless this technique is very useful to determine the range of the content in the sample. The EDX spectrum presented in Fig. 3 shows that our sample is only composed of $\mathrm{Si}, \mathrm{O}$ and $\mathrm{Au}$. The low amount of carbon detected on the spectra can be due to a

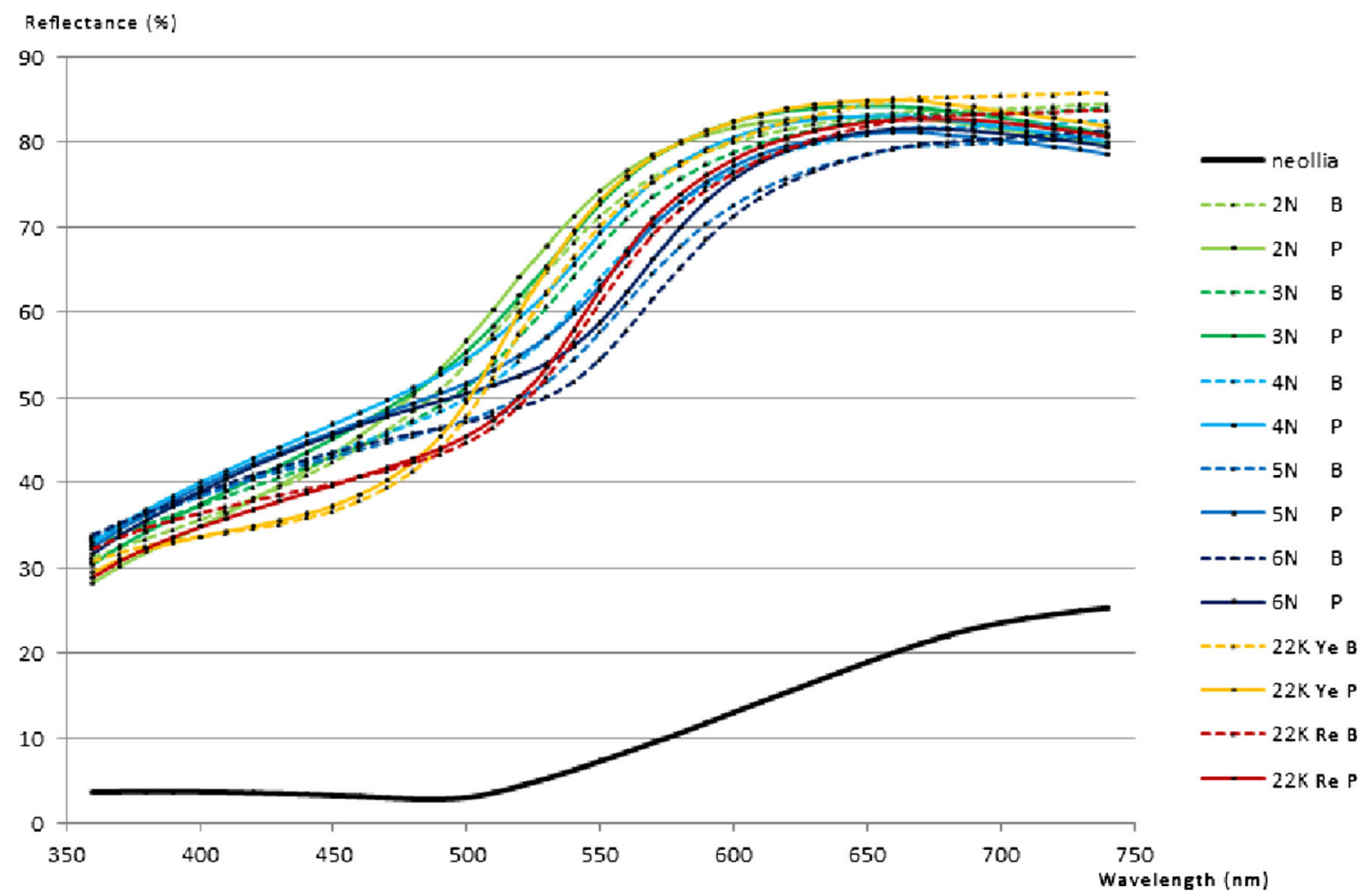

Fig. 5 Spectral curves of the 18-K deep red gold and the standard gold alloys provided by Varinor (2N, 3N, 4N, 5N, 6N, 22-K yellow gold, 22-K red gold and A1-derived material) 


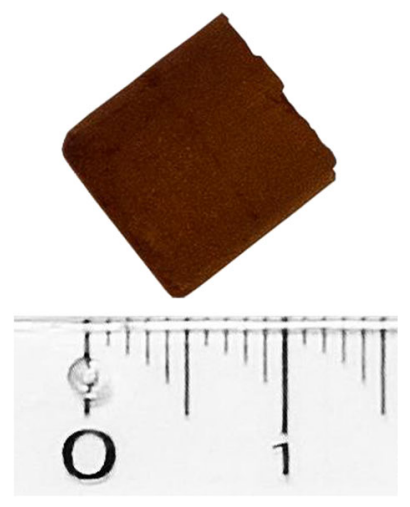

Fig. 6 Pellet of the presented material

surface contamination or to the carbon tape used to fix the sample during the SEM observation. As the cupellation technique is a standard method in Switzerland, we will preferentially take this result into account. However, both techniques show the formation of $18-\mathrm{K}$ red-coloured gold.

The colour of the piece is measured with a spectrophotocolorimeter, same specifications as cited beforehand. The $\mathrm{a}^{*} \mathrm{~b}^{*}$ values are respectively 18.31 and 21.82 . Figure 4 presents a plot of our measurement in the $\mathrm{a}^{*} \mathrm{~b}^{*}$ space. It is compared to the values of the $2 \mathrm{~N}, 3 \mathrm{~N}, 4 \mathrm{~N}, 5 \mathrm{~N}, 6 \mathrm{~N}, 22-\mathrm{K}$ yellow gold and $22-\mathrm{K}$ red gold standards provided by Varinor. With the $a^{*} b^{*}$ system, the higher the $a^{*}$ value is, the redder it is. Even though the $b^{*}$ values are in the same order of magnitude, the $a^{*}$ value of our sample is much higher, leading to a material much redder than the reddest 18 -K gold alloys $(5 \mathrm{~N})$.

Spectral curves of standard gold alloys provided by Varinor (Delémont, Switzerland) are presented in Fig. 5. It is worth noting that the spectral curves of all the traditional coloured gold are very similar even though a real difference can be observed macroscopically. For our developed $18-\mathrm{K}$ red gold, the reflectance is much lower. This can be partially attributed to the fact that the sample is neither polished nor brushed. However, we can notice that for the same material, the surface state (polished or brushed) does not modify radically the shape of the spectral curve. In our case, in between 370 and $480 \mathrm{~nm}$, the spectral curve is flat and has a reflectance of about $5 \%$ whereas for regular gold, this value is comprised between 30 and $48 \%$ in the same wavelength range. From 500 to $680 \mathrm{~nm}$, the reflectance increases linearly from 4 to $22 \%$ whereas traditional gold are characterized by a bump in the same wavelength range.

Figure 6 is a picture of our $18-\mathrm{K}$ red bulk gold.

\section{Conclusion}

We report in this study a new way to obtain deeply coloured gold materials using the surface plasmon resonance effect of gold nanoparticles. The resulting colour is markedly different from the one of traditional alloys. Thanks to our method, an entirely new range of coloured gold can be obtained, with much deeper colours than traditional gold alloys.
We also can obtain a deeply red 18-K bulk piece of gold, whose aspect is radically different from traditional gold. Our red gold is much redder than the reddest $18-\mathrm{K}$ gold on the market. The gold content is measured using EDX and the cupellation technique. Both techniques demonstrate that the gold rate of the pieces is higher than $75 \%$. To our knowledge, this is the first example of a deeply coloured piece of gold with a gold rate higher than $75 \%$ and made using the nanotechnology approach.

Acknowledgment The authors thank Jérôme Diaz from Konica Minolta (Lyon) for the use of the CM-5 spectrophotocolorimeter.

Open AccessThis article is distributed under the terms of the Creative Commons Attribution License which permits any use, distribution, and reproduction in any medium, provided the original author(s) and the source are credited.

\section{References}

1. Higby GJ (1982) Gold in medicine. Gold Bull 15(4):130-140

2. Kauffman GB (1985) The role of gold in alchemy. Part I. Gold Bull 18(1):31-44

3. Kauffman GB (1985) The role of gold in alchemy. Part II. Gold Bull 18(2):69-78

4. Kauffman GB (1985) The role of gold in alchemy. Part III. Gold Bull 18(3):109-119

5. Prince A, Raynor GV, Evans DS (1990) Phase diagrams of ternary gold alloys. The Institute of Metals, London

6. Roberts Errol FI, Clarke Keith M (1979) The colour characteristics of gold alloys. Gold Bull 12(1):9-19. doi:10.1007/BF03215099

7. McDonald Allen S, Sistare George H (1978) The metallurgy of some carat gold jewellery alloys. Gold Bull 11(3):66-73. doi:10.1007/ BF03215089

8. Rapson William S (1990) The metallurgy of the coloured carat gold alloys. Gold Bull 23(4):125-133. doi:10.1007/BF03214713

9. Cretu C, Van Der Lingen E (1999) Coloured gold alloys. Gold Bull 32(4):115-126. doi:10.1007/BF03214796

10. Corti CW (2004) Blue, black and purple! the special colours of gold. Santa Fe Symposium Albuquerque, USA

11. Klotz UE (2010) Metallurgy and processing of coloured gold intermetallics - part I: properties and surface processing. Gold Bull 43(1): 4-10. doi:10.1007/BF03214961

12. Fischer-Bühner J, Basso A, Poliero M (2010) Metallurgy and processing of coloured gold intermetallics - part II: investment casting and related alloy design. Gold Bull 43(1):11-20. doi:10.1007/ BF03214962

13. Supansomboon S, Maaroof A, Cortie MB (2008) "Purple glory": the optical properties and technology of $\mathrm{AuAl}_{2}$ coatings. Gold Bull 41(4):296-304. doi:10.1007/BF03214887

14. Lafait J et al (2009) Physical colors in cultural heritage: surface plasmons in glass, C.R. Phys 10(7):649-659. doi:10.1016/j.crhy. 2009.08.004

15. Freestone I, Meeks N, Sax M, Higgitt C (2007) The Lycurgus Cupa Roman nanotechnology. Gold Bull 40(4):270-277. doi:10.1007/ BF03215599

16. Wagner FE et al (2000) Before striking gold in gold-ruby glass. Nature 407:691-692. doi:10.1038/35037661

17. Lochbilher H (2009) Colored images generated by metallic subwavelength gratings. Opt Express 17(14):12189-12196. doi:10. 1364/OE.17.012189 
18. Edwards PP, Thomas J (2007) Gold in a metallic divided state-from faraday to present-day nanoscience. Angew Chem Int Ed 46:54805486. doi:10.1002/anie. 200700428

19. Murphy CJ (2002) Nanocubes and nanoboxes. Science 298:21392141. doi:10.1126/science. 1080007

20. Link S, Mohamed MB, El-Sayed MA (1999) Simulation of the optical absorption spectra of gold nanorods as a function of their aspect ratio and the effect of the medium dielectric constant. J Phys Chem B 103(16):3073-3077. doi:10.1021/jp990183f

21. Kelly KL, Coronado E, Zhao LL, Schatz GC (2003) The optical properties of metal nanoparticles: the influence of size, shape, and dielectric environment. J Phys Chem B 107(3):668-677. doi:10. 1021/jp026731y

22. Sosa IO, Noguez C, Barrera RG (2010) Optical properties of metal nanoparticles with arbitrary shapes. J Phys Chem B 107(26):62696275. doi:10.1021/jp0274076

23. Persson BNJ (1993) Polarizability of small spherical metal particles: influence of the matrix environment. Surf Science 281(1-2):153-162

24. Kreibig U (2008) Interface-induced dephasing of Mie plasmon polaritons. Appl Phys B 93(1):79-89. doi:10.1007/s00340-008-3213-1

25. Turkevich J, Stevenson P, Hillier C (1951) A study of the nucleation and growth processes in the synthesis of colloidal gold. Discuss Faraday Soc 11:55-75. doi:10.1039/DF9511100055

26. Turkevich J (1985) Colloidal gold. Part I. Gold Bull 18(3):86-91. doi:10.1007/BF03214690

27. Turkevich J (1985) Colloidal Gold. Part II. Gold Bull 18(4):125-131. doi:10.1007/BF03214694
28. Frens G (1973) Controlled nucleation for the regulation of the particle size in monodisperse gold suspensions. Nat Phys Sci 241:20-22. doi: 10.1038/physci241020a0

29. Kimling J, Maier M, Okenve B, Kotaidis V, Ballot H, Plech A (2006) Turkevich method for gold nanoparticle synthesis revisited. J Phys Chem B 110(32):15700-15707. doi:10.1021/jp061667w

30. Chen Y, Gu X, Nie C-G, Jiang Z-Y, Xie Z-X and Lin C-J (2005) Shape controlled growth of gold nanoparticles by a solution synthesis, Chem. Commun., 4181-4183 DOI:10.1039/B504911C

31. Wu H-L, Tsai H-R, Hung Y-T, Lao K-U, Kiao C-W, Chung P-J, Huang J-S, Chen I-C, Huang MH (2011) A comparative study of gold nanocubes, octahedra, and rhombic dodecahedra as highly sensitive SERS substrate. Inorg Chem 50(17):8106-8111. doi:10. 1021/ic200504n

32. Vigderman L, Khanal BP, Zubarev ER (2012) Functional gold nanorods: synthesis, self-assembly, and sensing applications. Adv Mater 24:4811-4841. doi:10.1002/adma.201201690

33. Kealley CS, Cortie MB (2010) A computational exploration of the color gamut of nanoscale hollow scalene ellipsoids of $\mathrm{Ag}$ and $\mathrm{Au}$. Plasmonics 5(1):37-43. doi:10.1007/s11468-009-9112-4

34. Johnston JH, Lucas KA (2011) Nanogold synthesis in wool fibers: novel colourants. Gold Bull 44(2):85-89. doi:10.1007/s13404-011$0012-\mathrm{y}$

35. Iwakoshi A et al (2005) Coating materials containing gold nanoparticles. Gold Bull 38(3):107-112. doi:10.1007/BF03215244*

36. Pujol O et al (2011) Matériau composite colore comprenant des nanoparticules, Brevet EP 1887052 A1, 06/04/ 